\title{
22 Inclusive education for students from refugee or migrant backgrounds
}

\author{
Clemence Due
}

\section{How to use this policy}

Students with refugee and migrant backgrounds bring with them a range of complex needs as well as strengths. Importantly, students with refugee or migrant backgrounds are diverse and have educational needs which vary depending on context. As such, this policy example is intentionally broad and school policy creators are encouraged to delete and build upon suggestions below to create a policy that best represents their school. This policy encourages collaboration in local context with parents, broader family members, and communities, as well as education departments to ensure that the policy meets the needs of all stakeholders. Policies concerning students with refugee and migrant backgrounds should be implemented school-wide (e.g., rather than only within intensive English classes or sections of schools), given the large body of evidence concerning whole of school approaches.

[To adapt and use this policy, delete or modify the text as indicated]

[INSERT name of school] Inclusive education for students from refugee or migrant backgrounds

\section{Rationale}

Students with refugee and migrant backgrounds face a range of challenges, including negotiating changing identities, challenges learning about and "fitting in" to a new culture, and issues such as discrimination or social exclusion (Woods, 2009; Riggs \& Due, 2011). In addition, they may have previously experienced issues that have the potential to affect their ongoing psychological and physical wellbeing, such as experiences of torture, trauma, dislocation, and disrupted education (Christie \& Sidhu, 2002). Taken together, these factors lead to a complex interplay of issues that affect young people's sense of wellbeing and identity in their new country (Correa-Velez et al., 2010; Gifford et al., 2009). These complexities are particularly salient within educational contexts, where students with migrant or refugee backgrounds frequently encounter the sociocultural and physical environments of their resettlement 
countries for the first time. Schools can provide an important avenue for support for young people with refugee or migrant backgrounds, with previous research indicating that positive educational experiences can boost self-esteem and resilience, encourage community participation and the development of peer relationships, and enable young people to build on their existing skills, knowledge, and abilities (Block et al., 2014; Correa-Velez et al., 2010; Keddie, 2012; de Heer et al., 2015).

Moreover, the educational experiences of young people with migrant or refugee backgrounds are important due to the critical role that education has to play in a range of developmental outcomes for young people, including not only intellectual and cognitive development along with academic growth for several years after arrival in a resettlement country (Motti-Stefanidi \& Masten, 2013), but also in relation to a range of areas related to childhood development and wellbeing more broadly. Early experiences of education are particularly important in this regard and can play a crucial role in developing school engagement, which is particularly important in relation to ongoing educational achievement and ensuring that a gradual process of disengagement leading to attrition does not occur (Marks, 2000; Fredricks et al., 2004).

\section{Purpose}

The purpose of this policy is to outline whole school approaches for inclusive education for students with refugee and migrant backgrounds for all members of a school community, to ensure that refugee and migrant students are supported at school and their strengths recognised.

\section{Scope}

This policy applies to all members of the school community, including present and past students, teachers, other staff such as bi-lingual bi-cultural workers and support staff, school leaders, parents, and broader refugee and migrant communities associated with the local school contexts. Whole school, inclusive approaches are vital when working with this cohort of students.

[INSERT specific roles and responsibilities of individuals or teams]

\section{Policy statement}

\section{School management}

[INSERT name of school] works closely with the families of students with migrant and refugee backgrounds as well as their broader communities where appropriate. This includes invitations to school events, translation of materials where possible, and engagement with specific cultural/ethnic community events (Taylor \& Sidhu, 2011). 
[INSERT name of school] enables multiple opportunities for students from refugee and migrant backgrounds to contribute to school culture and processes, so that their knowledge and strengths are reflected in the school environment. Educators work together to ensure that this involvement is school-wide rather than only in any specialised classes (Pugh et al., 2012).

[INSERT name of school] has a key focus on ensuring whole school approaches that include consideration and active focus on students with refugee and migrant backgrounds and their contributions to and inclusion within the school community (Pugh et al., 2012; Keddie, 2011; Keddie, 2012).

Efforts are made at [INSERT name of school] to ensure that transition from specialised English language classes or schools into mainstream classes at [INSERT name of school] is supported. This includes allocation of resources where possible, sufficient orientation time for students, and visits between classes or schools where appropriate (Fischer, 2010).

Training and professional development concerning issues faced by students with refugee or migrant backgrounds is provided for all teachers at [INSERT name of school]. This includes training concerning trauma-informed, culturally responsive education (Matthews, 2008; Due et al., 2015).

[INSERT name of school] supports teachers who work with students with refugee and migrant backgrounds including recognition that these teachers may experience vicarious trauma. [INSERT name of school] has appropriate referral pathways to mental health services for these teachers (Baak et al., 2020).

[INSERT name of school] has strategies in place to evaluate any content specific to students with refugee or migrant backgrounds, including provision of English language education (Woods, 2009).

\section{Teachers}

Teachers at [INSERT name of school] work with whole school approaches to ensure that the strengths of students with refugee and migrant backgrounds are foregrounded in the school environment. This includes, for example, ensuring that subjects that do not rely on English (such as art or sport) are included in classes as much as possible (Pugh et al., 2012; Due et al., 2016a).

Teachers at [INSERT name of school] engage with parents and communities of students with refugee and migrant backgrounds to ensure that they understand the context of students' lives and that school is a culturally safe space for students to be (Block et al., 2014; Keddie, 2012).

Teachers at [INSERT name of school] endeavour to work within traumainformed frameworks in recognition of the higher burden of mental illness (and particularly trauma) within this cohort of students (Baak et al., 2020). 


\section{Students}

[INSERT name of school] encourages students to support each other, with particular emphasis on interactions between those students who have refugee or migrant backgrounds and those who do not (Due et al., 2016a).

At [INSERT name of school] all students are encouraged to use their personal strengths and to draw upon their cultural background, first or additional languages, and existing knowledge to inform their current learning (Due et al., 2016b)

[INSERT name of school] works with students to provide appropriate language resources, and students for whom English is an additional language are encouraged to ensure they engage with these resources (de Heer et al., 2016; Olliff \& Couch, 2005).

All students at [INSERT name of school] are encouraged to be inclusive and respectful, particularly in relation to culture and ethnicity (Walton et al., 2014).

\section{Parents and communities}

[INSERT name of school] provides multiple communication channels for parents including translation of materials as appropriate for larger language groups. Parents are encouraged to be actively engaged with these communication channels (Oliff \& Couch, 2005).

The school seeks feedback from parents and broader communities about their satisfaction with the [INSERT name of school], including its level of involvement within refugee and migrant background communities (Keddie, 2012).

\section{Authorship}

Dr Clemence Due, The University of Adelaide

[INSERT RELEVANT STAFF MEMBERS]

\section{Related policy and documents}

[INSERT RELEVANT POLICY AND DOCUMENTS]

Wellbeing policy

Inclusion policies

Cross/multi-cultural educational policies

Counselling policies

English literacy policies

\section{Date of ratification}

This policy was ratified on the [INSERT DATE]. 


\section{Rating of evidence base}

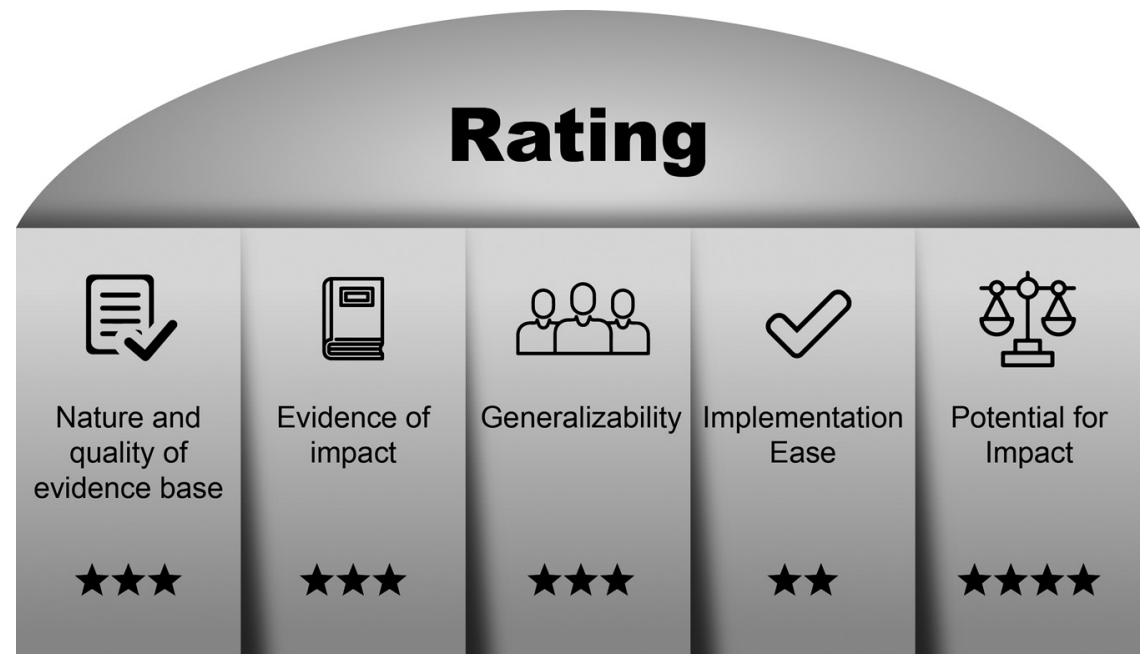

Figure 22.1. Inclusive Education for Students from Refugee or Migrant Backgrounds Rating of Evidence.

Author Note. The evidence base concerning best practice educational approaches for students with refugee and migrant backgrounds is generally good, although the focus is on secondary school students rather than primary school students. Some studies are smaller and context-specific, making overall interpretation of results difficult at times. Exploring impact as a result of these policies is a relatively newer area of research and thus findings are emerging. There are some clear principles that have a strong evidence base across contexts, such as the benefit of whole school approaches. However, there will be variations in practice based on cultural, ethnic, or language backgrounds of students, as well as the situation of the school itself, thus generalisability needs to be considered with care. Some of the policy suggestions here will require additional resources or training of staff.

\section{Date of review}

This policy will be reviewed by [INSERT DATE].

\section{Recommended reading}

Allen, K. A., \& Boyle, C. (Eds.) (2018). Pathways to Belonging: Contemporary research in school belonging. Leiden, The Netherlands: BRILL | Sense. https://doi.org/10.1163/9789004386969

Due, C., Riggs, D.W. and Augoustinos, M. (2015). The education, wellbeing and identity of children with migrant or refugee backgrounds. Report for the Department of Education and Child Development. https://doi.org/10. 13140/RG.2.1.1933.5529 


\section{References}

Baak, M., Miller, E., Ziersch, A., Due, C., Masocha, S., Ziaian, T. (2020). The role of schools in identifying and referring refugee background young people who are experiencing mental health issues. The Journal of School Health, 90(3), 172-181. doi:10.1111/josh.12862

Block, K., Cross, S., Riggs, E., \& Gibbs, L. (2014). Supporting schools to create an inclusive environment for refugee students. International Journal of Inclusive Education, 18, 1337-1355. doi:10.1080/13603116.2014.899636

Christie, P., \& Sidhu, R. (2002). Responding to globalisation: Refugees and the challenges facing Australian schools. Mots Pluriels, 21. http://motspluriels.arts.uwa.edu. au/MP2102pcrs.html

Correa-Velez, I., Gifford, S. M., \& Barnett, A. G. (2010). Longing to belong: Social inclusion and wellbeing among youth with refugee backgrounds in the first three years in Melbourne, Australia. Social Science and Medicine, 71, 1399-1408. doi:10.1016/j.socscimed.2010.07.018

de Heer, N., Due, C., \& Riggs, D. W. (2015). "It will be hard because I will have to learn lots of English": Experiences of education for children with migrant backgrounds in Australia. The International Journal of Qualitative Studies in Education, 29(3), 297-319. doi:10.1080/09518398.2015.1023232

Due, C., Riggs, D. W., \& Mandara, M. (2015). Educators' experiences of working in Intensive English Language Programs: The strengths and challenges of specialised English language classrooms for students with migrant and refugee backgrounds. The Australian Journal of Education, 59(2), 169-181. doi:10.1177\% 2F0004944115587365

Due, C., Riggs, D. W., \& Augoustinos, M. (2016a). Experiences of school belonging for young children with refugee backgrounds. The Educational and Developmental Psychologist, 33(1), 33-53. doi:10.1017/edp.2016.9

Due, C., Riggs, D. W., \& Augoustinos, M. (2016b). Diversity in Intensive English Language Centres in South Australia: Sociocultural approaches to education for students with migrant or refugee backgrounds. International Journal of Inclusive Education, 20(12), 1286-1296. doi:10.1080/13603116.2016.1168874

Fischer, M. (2010). Immigrant educational outcomes in new destinations: An exploration of high school attrition. Social Science Research, 39(4), 627-641. doi:10.1016/j.ssresearch.2010.01.004

Fredricks, J., Blumenfeld, P., \& Paris, A. (2004). School engagement: potential of the concept, state of evidence. Review of Educational Research, 74, 59-109. doi:10.3102\% 2F00346543074001059

Gifford, S., Correa-Velez, I., \& Sampson, R. (2009). Good starts for recently arrived youth with refugee backgrounds: Promoting wellbeing in the first three years of settlement in Melbourne, Australia. Refugee Health Research Centre \& Victorian Foundation for Survivors of Torture, Melbourne. http://hdl.handle.net/1959.3/222827

Keddie, A. (2011). Supporting minority students through a reflexive approach to empowerment. British Journal of Sociology of Education, 32, 221-238. doi:10.1080/ 01425692.2011 .547307

Keddie, A. (2012). Refugee education and justice issues of representation, redistribution and recognition. Cambridge Journal of Education, 42(2), 197-212. doi:10.1080/ 0305764X.2012.676624 
Marks, H. (2000). Student engagement in instructional activity: Patterns in the elementary, middle, and high school years. American Educational Research Journal, 37, 153-184. doi:10.2307/1163475

Matthews, J. (2008). Schooling and settlement: Refugee education in Australia. International Studies in Sociology of Education, 18(1), 31-45. doi:10.1080/09620210802195947

Motti-Stefanidi, F., \& Masten, A. S. (2013). School success and school engagement of immigrant youth: A risk and resilience developmental perspective. European Psychologist, 18(2), 126-135. doi:10.1027/1016-9040/a000139

Olliff, L., \& Couch, J. (2005). Pathways and pitfalls: The journey of refugee young people in and around the education system in Greater Dandenong, Victoria. Youth Studies Australia, 24, 42-46. https://search.informit.com.au/documentSummary; $\mathrm{dn}=$ 028489220266953;res=IELHSS

Pugh, K., Every, D., \& Hattam, R. (2012). Inclusive education for students with refugee experience: whole school reform in a South Australian primary school. The Australian Educational Researcher, 39(2), 125-141. doi:10.1007/s13384-011-0048-2

Riggs, D. W., \& Due, C. (2011). (Un)common ground?: English language acquisition and experiences of exclusion amongst new arrival students in South Australian primary schools. Identities: Global Studies in Culture and Power, 18(3), 273-290. doi:10.1080/1070289X.2011.635373

Taylor, S., \& Sidhu, R. K. (2012). Supporting refugee students in schools: What constitutes inclusive education? International Journal of Inclusive Education, 16(1), 39-56. doi:10.1080/13603110903560085

Walton, J., Priest, N., Kowal, E., et al. (2014). Talking culture? Egalitarianism, color blindness and racism in Australian elementary schools. Teaching and Teacher Education, 39, 112-122. doi:10.1016/j.tate.2014.01.003

Woods, A. (2009). Learning to be literate: Issues of pedagogy for recently arrived refugee youth in Australia. Critical Inquiry in Language Studies, 6, 81-101. doi:10.1080/ 15427580802679468 